\title{
AN ANALYSIS OF SOME UPSETTING TESTS FOR ASSESSING THE COLD FORGEABILITY OF STEELS
}

\section{R. Sowerby*, N. Chandrasekaran*,** N. L. Dung**}

and O. Mahrenholtz**

${ }^{*}$ Department of Mechanical Engineering, McMaster University, Hamilton, Ontario L8S 4L7,

** Structural Mechanics Division, Technical University of Hamburg-Harburg, Eissendorferstr. 38, 2100 Hamburg 90, Federal Republic of Germany

\section{ABSTRACT}

The article provides some experimental data and some associated theoretical work, which should aid in assessing the suitability of certain steels designated for cold forging operations. The compression of a circular cylinder is often used to assess cold forgeability. Alternative specimen geometries for laboratory upsetting tests are illustrated herein. It is Alternative specim for a demonstrated that, for a given material, the up secimen geometry influence on the shape and levelor the strain path at a point on the equatorial free surface of the test piece. The so-call collar test elinich of the specimen from presented which indicates that tho results from the different upsetting tests do not ie on single fracture line, as proposed by Kuhn. Four distinct upsetting tests are modelled using a finite element (F.E.) analysis, based on a rigid-plastic, incompressible, rate-insensitive solid. The material characteristics were obtained from uniaxial compression tests on AISI 1045 and 1144 steels in a spheroidized and annealed condition. Experimentally determined strain path data and geometric changes could be described quite accurately using the F.E. analysis, a reliable fracture criterion needs to be established before the F.E. model can predict the fracture limit.

\section{KEYWORDS}

Cracking in materials; upsetting tests; al ternative specimen geometries element (F E.) analysis, cold forgeability ; strain path data ; surface cracks.

\section{INTRODUCTION}

It is exceedingly difficult to define quantitatively the ability of a material to be warm or cold forged. Cracking in materials designated for forging operations generally occurs by ductile fracture mechanisms. The limit of the forming process is governed by a complicated interplay of such factors as material structure (the nature of the second phase particles, inclusions, etc.), temperature, rate of deformation, tool and workpiece geometry, and the friction at the interface of the tool(s) and the workpiece.

A test often used to assess the cold forgeability of a material is the upsetting of a circular cylinder, see Fig. 1(a), until the appearance of surface cracks. This simple laboratory 

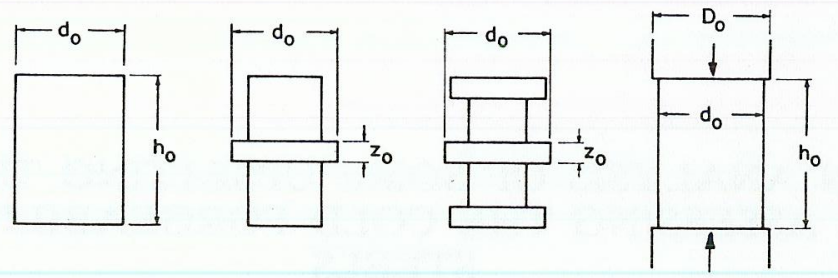

a) COMPRESSION

b) COLLAR TEST

c) COLLAR TEST

d) PUNCH TEST

A $\left\{d_{0}=10 \mathrm{~mm}\right.$

B $\left\{\begin{array}{l}d_{0}=15.6 \mathrm{~mm} \\ z_{0}=3 \mathrm{~mm}\end{array}\right.$

c $\left\{\begin{array}{l}d_{0}=12.5 \mathrm{~mm} \\ z_{0}=3 \mathrm{~mm}\end{array}\right.$

$D\left\{\begin{array}{l}D_{0}=15 \mathrm{~mm} \\ d_{0}=14 \mathrm{~mm} \\ h_{0}=21 \mathrm{~mm}\end{array}\right.$

MATERIALS $\left\{\begin{array}{l}\text { ANNEALED STEELS: } 1045(a), 1144(a) \\ \text { SPHEROIDIZED STEELS: } 1045(\mathrm{~s}), 1144(\mathrm{~s})\end{array}\right.$

Fig. 1 Geometry of Test Pieces.

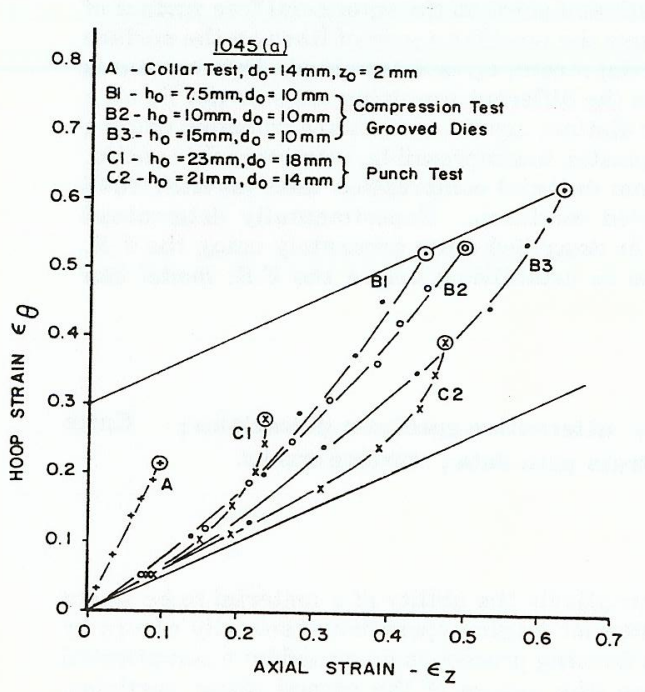

a) STRAIN PATH

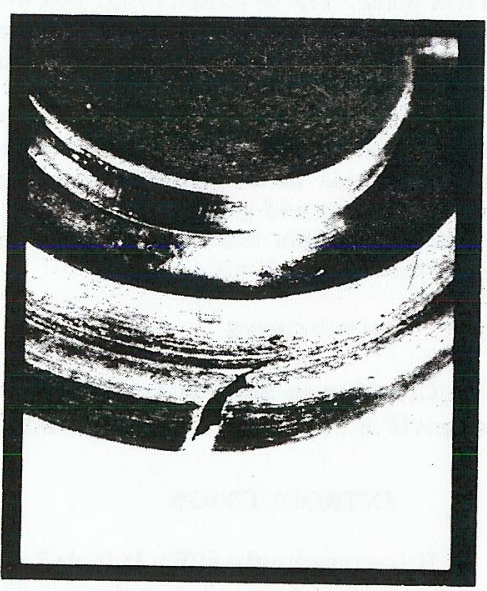

b) SURFACE CRACK IN COLLAR TEST (FIG. 1b)
Fig. 2 Experimentally Determined Strain Paths for the Upsetting Tests. test (usually performed quasi-statically) is obviously not representative of many industrial hrying operations. However, open die forging and heading can be regarded as upsetting aperations, and the laboratory test does permit a comparison to be made between different materials in an upsetting process.

One drawback when upsetting circular cylinders is the need to mark a grid of lines (or iveles) on the surface to obtain a measure of the strains at fracture. Furthermore, when using duetile materials, very high loads are required (even with small diameter test pieces) to promote surface cracks; therefore, high capacity testing machines are called for. To overcome these disadvantages, some alternative testing procedures were explored by Brownrigg et al. III. As a result of the work of Ref. [1] and subsequent studies [2-4], the tests shown in Figs. I(b) to (d) were proposed. All of these upsetting operations resulted in a lower fracture strain vis $\mathrm{A}$ vis the test method of Fig. 1(a). The test shown in Figs. 1(b) and (c) has been named the collar test, while that of Fig. 1(d) is referred to as the punch test. The collar test eliminates the need for a surface grid, since the hoop, $\varepsilon_{\theta}$, and axial, $\varepsilon_{z}$, strains can be obtained by ineasuring the diameter and thickness, respectively, of the collar.

The investigations performed in Refs. [1-4], using the upsetting tests of Fig. 1, have indicated that, for a given material, the fracture strains do not lie on a straight line with a lope of $\varepsilon_{\theta} / \varepsilon_{2}=-\frac{1}{2}$. A straight line fracture locus had been proposed by Lee and Kuhn [5], and supported by other workers, but primarily for the upsetting of circular cylinders.

Some fracture data [1] for a 1045 steel is shown in Fig. 2. It is evident that the shape and level of the $\varepsilon_{\theta}-\varepsilon_{Z}$ strain path is very dependent upon the specimen geometry. The essentially linear strain path and the low fracture strains for the collar test of Fig. 1(b) are typical of the behaviour of a variety of commerical steels tested in Refs. [1-4]. For the upset losts depicted in Figs. 1 (a) and (d) the $\varepsilon_{0}-\varepsilon_{z}$ strain data were obtained by measuring a 1.27 mm square grid which had been photographically printed on each test piece at its mid-height.

The purpose of the present study was to perform a finite element (F.E.) analysis for each of the upsetting tests shown in Figs. 1(a) to (d), and to compare the theoretical each of the upsetting tests shown in Figs. 1(a) to (d), and to compare the theoretical predictions with some of the experimental data gathered in Refs. [1-4]. The materials 1144 steel is essentially the 1045 grade, but with a higher sulphur content and a concomitant 1144 steel is essentially the 1045 grade
larger volume fraction of inclusions.

\section{MODELLING OF THE UPSETTING TESTS}

True stress $(\bar{\sigma})$-strain $(\bar{\varepsilon})$ data for each of the materials were obtained from compression tests on cylindrical test pieces. The tests were interrupted to renew the lubrican on the end faces of the cylinders. The stress-strain curves were fitted by the following empirical expression

$$
\bar{\sigma}=\mathrm{A}(\mathrm{B}+\bar{\varepsilon})^{\mathrm{n}}
$$

The parameters A, B and $\mathrm{n}$ were determined using an optimization routine to provide the best fit to the experimental data. The results are given in Table 1, and the data were used in the F.E. analysis. The material is assumed to be a rigid, incompressible, rate-insensitive solid.

Due to the symmetry of the specimens shown in Fig. 1, only one-quarter of the test piece needs to be considered in the analysis. Up to 100 quadrilateral elements were used in the F.E. mesh to characterize each specimen.

In the present study, the frictional stress, $\tau$, at the interface of the workpiece and the compression platens was assumed to be represented by

$$
\tau=\mathrm{mk},
$$


where $0 \leq \mathrm{m} \leq 1$ and $\mathrm{k}$ is the shear stress of the material. For the compression tests of Fig. $1(\mathrm{a})$, the following conditions were considered:

i) $\quad 0 \leq \mathrm{m} \leq 0.25$, to represent a well lubricated condition

ii) $\quad \mathrm{m}=1.0$ to represent an unlubricated condition but with material shearing across the platens, i.e. the shear stress of the material is reached and slides across the platens,

iii) sticking friction, such that there is no relative sliding once the material comes into contact with the platens.

For the punch tests of Fig. 1(d), m was selected as either $0,0.1,0.25$ or 1.0. For each of the collar tests in Figs. 1(b) and (c), a sticking friction condition was assumed. With the geometry shown in Fig. 1(b), material from the cylinder wall is folded back to contact and adhere to the platens as the test progresses. No lateral flow of the end flanges is possible with the test piece shown in Fig. 1(c), since they locate in recesses in the compression platens. In this case, the shown in Fig. 1(c), since they locate in recesses in the compression platens. In this case, the cylindrical portions of the test piece between the end flanges and central collar are bulged out. At higher reductions, the bulging can be so severe that contact is made with the end flange and the central collar. Overlapping of the F.E. mesh can ensue and the numerical solution is inated at this stage. Refs [6-9].

Details of the finite element analysis and of the algorithms employed can be found in

Table 1

\begin{tabular}{llllll}
\hline & \multirow{2}{*}{ Steel } & & $\begin{array}{c}\text { A } \\
\text { (MPa) }\end{array}$ & $\mathrm{n}$ & $\mathrm{B}$ \\
\hline \multirow{2}{*}{1045} & (a) & 1049 & 0.18 & 0.03 \\
& (s) & 1014 & 0.28 & 0.05 \\
\hline \multirow{2}{*}{1144} & (a) & 1092 & 0.14 & 0.03 \\
& (s) & 1250 & 0.26 & 0.05 \\
\hline
\end{tabular}

Initial yield strength $\mathrm{Y}_{0}=\mathrm{AB}^{\mathrm{n}}$

\section{RESULTS AND COMPARISON WITH EXPERIMENTAL DATA}

\section{1) Strain Path}

Figure 3 shows the comparison between the predicted and experimentally determined $\varepsilon_{\theta}-\varepsilon_{z}$ strain path for the compression test of Fig. 1(a). The material was an AISI 1045 steel in either a spheroidized (s) or annealed (a) condition. The strains were evaluated at a point on the equatorial free surface. The results are quite typical, and by altering the interfacia frictional condition in the F.E. model, excellent agreement can be obtained.

Some results for the punch test, see Fig. 1(d), are given in Fig. 4 for an annealed 1045 steel. Predicted and experimental data for the collar test of Fig. 1(b) is illustrated in Fig. 5 Again, the material is a 1045 steel in either an annealed or spheroidized condition. The strain
COMPRESSION TESTS A

1045 (a\& s)

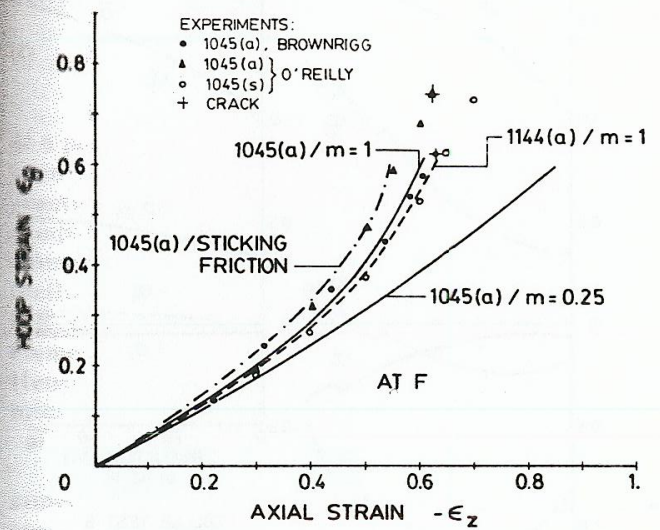

Fig. 3 Predicted and Experimentally Determined Strain Paths for the Compression Test of Fig. 1(a).

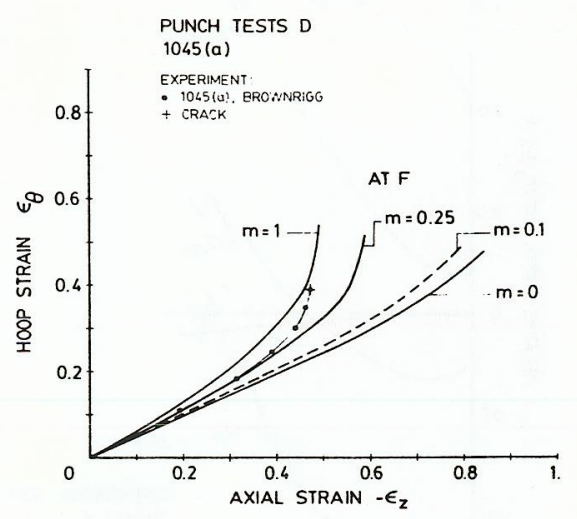

Fig. 4 Predicted and Experimentally Determined Strain Paths for the Punch Test of Fig. 1(d)

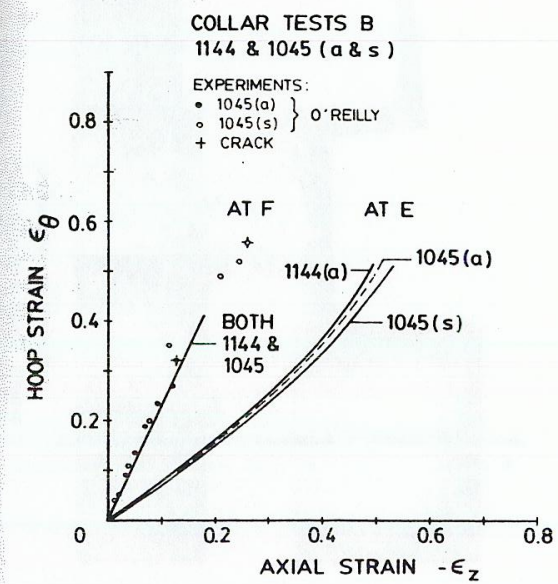

a) STRAIN PATH

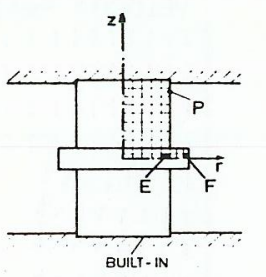

THE BEGINNING

b) DEFORMATION MODES

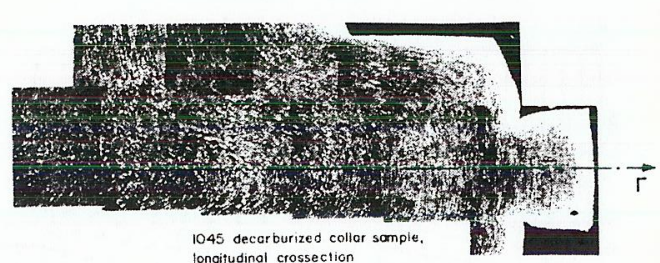

c) EXPERIMENT: FLOW PATTERN [4]

Fig. 5 Predicted and Experimentally Determined Strain Paths for the Collar Test. 


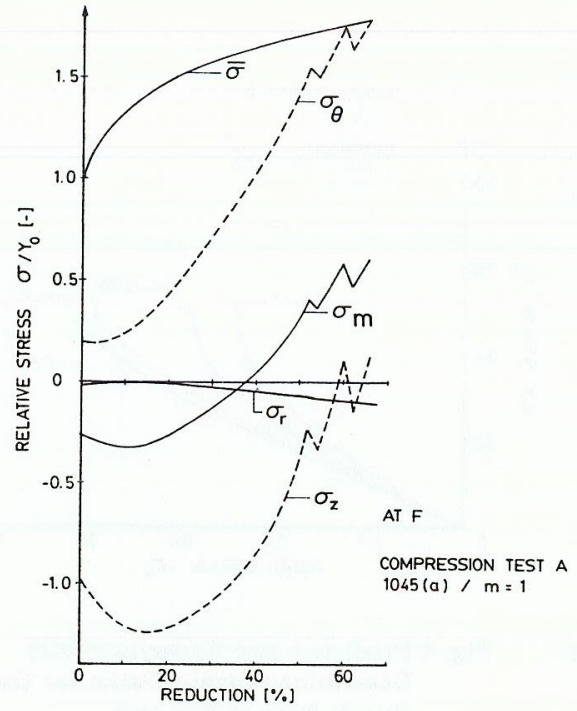

Fig. 6 Predicted Surface Stresses as a Functio of Reduction for the Compression Test of Fig. 1(a).

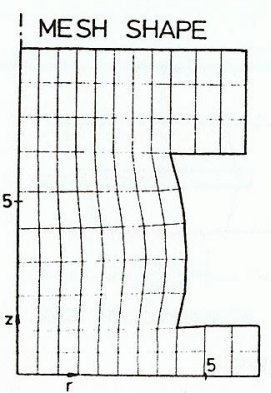

VELOCITY FIELD

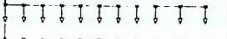

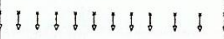
6061060101 1616160519

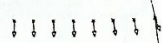
$1+6+136$ $16 \sin 2 x$ $1, \cdots \cdots$ $\because \cdots \cdots \cdots$

a) AT 10\% REDUCTION
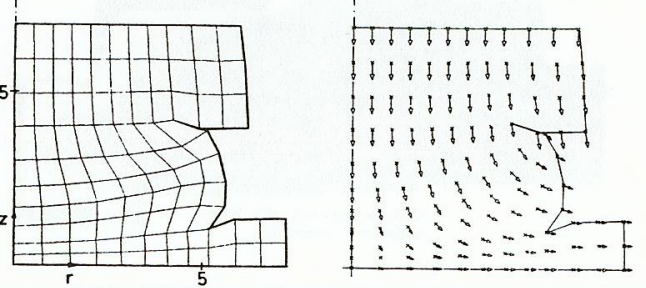

b) AT 34\% REDUCTION

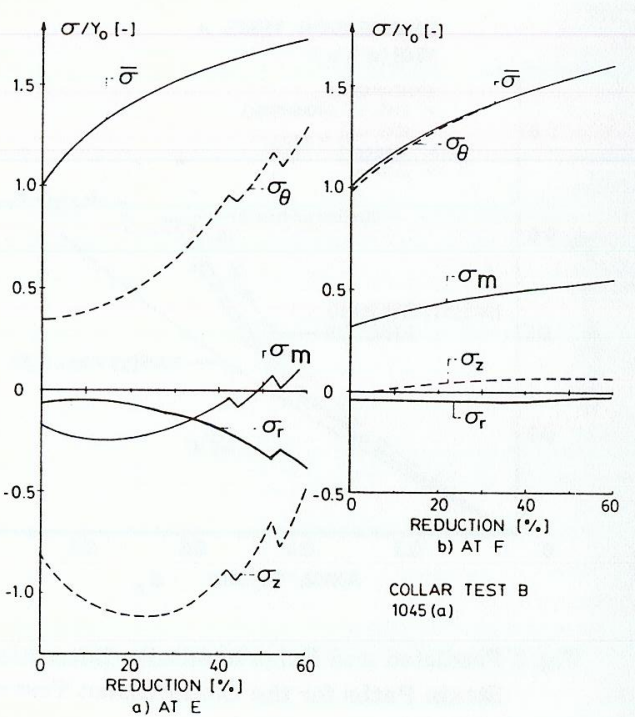
Reduction for the Collar Test of Fig. 1(b). (a) At a Point in the Interior (b) At the Free Surface

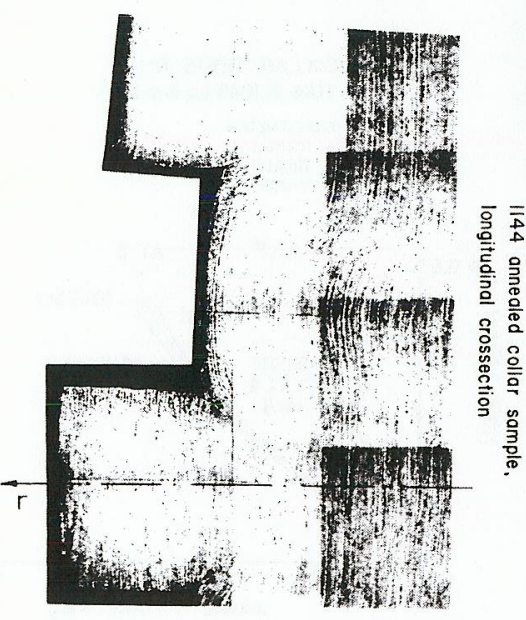

c) EXPERIMENT: FLOW PATTERN [4]
Fig 7 Predicted Stresses as a Function of

path is calculated for two locations in the collar specimen. The location $F$ is a point on the free surface of the collar, while the location $\mathrm{E}$ is an interior point - see the inset diagram in Fig. 5.

\section{ii) Stress Calculations}

Figure 6 shows the calculated hoop, $\sigma_{\theta}$, axial, $\sigma_{\mathrm{z}}$, radial, $\sigma_{\mathrm{r}}$, and hydrostatic stress, $\sigma_{\mathrm{m}}$ at a point on the equatorial free surface during the compression test. The calculations have been performed for an annealed 1045 steel, assuming sliding friction with $\mathrm{m}=1.0$. In pructice, $\sigma_{r}$ should be zero at the free surface. The small negative value of this stres component in the F.E. analysis arises because an average value is calculated within an olement, and only one side of the element is contiguous with the free surface. The small oscillations in some of the stress components at larger reductions is another feature of $\mathrm{F} \mathrm{E}$ calculations. The analysis allows for on com clement) being folded from the side of the cylinder to com into llence, there is an abrupt change in the contact area. These uns. minimized by reducing the size of the mesh.

Similar calculations for the collar test of Fig. 1(b) are shown in Fig. 7; again, for an annealed 1045 steel. The calculations have been performed for two locations within the specimen referred to earlier, i.e. point $E$ shown in Fig. 7(a) and point $F$ in Fig. 7(b)

Note that for all the upsetting tests, the theory predicts that the hydrostatic stress at the free surface the free surface becomes progressively more tensile as the deformation proceeds. For the collar tests, the hydrostatic stress is tensile from the outset, while for the compression and increasing interfacial friction.

\section{iii) Material Flow Patterns}

The F.E. analysis permits the determination of the velocity or displacement vectors of ach point within the mesh during the course of an upsetting operation. In the present work, the hardening behaviour of the material had little influence on the gross flow characteristic in any given test. Figure 8 illustrates the results that can be obtained from the compute program. The diagram pertains to the collar test of Fig. 1(c) for a spheroidized 1144 steel.

\section{CONCLUSIONS}

Previous experimental studies [1-4] and the present F.E. calculations (also in Ref. [8] have demonstrated the influence of the specimen geometry on the shape of the $\varepsilon_{\theta}-\varepsilon_{z}$ strain path during upsetting operations. In turn, the strain path dictates (in a continuum sense) the ussociated stress state, and together they influence the events leading to fracture. The F.E nnalysis used herein is not capable of revealing the micro-mechanisms which actually lead to fracture. The material characteristics are accounted for only through the stress-strain behaviour.

The experimental stress-strain curves for the two steels, subjected to the two heat Ireatments, were quite distinct, and yet this was not reflected in any significant way in the various F.E. calculations. The experiments demot reflected in any significant way in the upheroidized condition was superior to the annealed condition. Furthermore the 1144 , the was inferior to the 1045 grade. Consequently additional information needs to be in 144 grade into the F.E. model before it can be used to predict the information needs to be incorporated absence of a truly predictive failure criterion is a shortcoming not only of the present work but of the majority of F.E. studies of sheet and bulk metal forming operations. However, it is

Fig. 8 Predicted Velocity Field and Mesh Shape for the Collar Test of Fig. 1(c). 
encouraging that the present analysis is capable of predicting exterior (contour) shape changes and the strain path at the equatorial free surface during the various upsetting tests. Consequently, some confidence can be placed on the predicted stress and strain states (at least, in a macroscopic sense) at any point within the body of the specimen throughout the least, in a macroscopic sense) at any point within the body of the specimen throughout the CDC 6400 computer to obtain the results for the stress and strain states and the flow patterns for a complete upsetting test.

\section{ACKNOWLEDGEMENTS}

The authors would like to thank the Natural Sciences and Engineering Research Council of Canada and the Department of Energy, Mines and Resources (CANMET) for financial support of this work.

\section{REFERENCES}

[1] Brownrigg, A., Duncan, J.L. and Embury, J.D., "Free Surface Ductility of Steels in Cold Forging", Internal Report, McMaster University, Hamilton, Ontario, Canada, 1979 .

[2] Chandrasekaran, N., Brownrigg, A., Duncan, J.L., Embury, J.D. and Sowerby, R., "The Assessment of the Free Surface Strains and Stresses During the Upsetting of Circular Cylinders", Script Met., 16, (1982), 697- 701.

[3] Sowerby, R., O'Reilly, I., Chandrasekaran, N. and Dung, N.L., "Materials Testing for Cold Forging", Proc of ASME's Winter Annual Meeting, Session on "Materials in Manufacturing", Boston, MA, November 1983, to be published in J. Eng. Mat. \& Tech. 106, (1984).

[4] O'Reilly, I. "Flow and Fracture During Compression Tests of Cold Forging Steels" M.Eng. Thesis, McMaster University, Hamilton, Ontario, Canada, 1983.

[5] Lee, P.W. and Kuhn, H.A., "Fracture in Cold Upset Forging - A Criterion and Model", Metall. Trans., 4 , (1973), 969-974.

[6] Dung, N.L.,"Ein Beitrag zur Berechnung instationärer starr-plastischer Formänderungen mit einer Finite-Element-Methode", Fortschr.-Ber. VDI-Z. Reihe Nr. 46 (1981).

[7] Dung, N.L. and Mahrenholtz, O., in "Proc. Int. Conf. on Numerical Methods in Industrial Forming Processes", (Eds. J.F.T. Pittman et al.), Swansea, U.K., 187-196, Pineridge Press, 1982.

[8] Dung, N.L., "Finite Element Modelling of Upsetting Test", Metal Forming Research Report No. 83-013, McMaster University, Hamilton, Ontario, Canada, 1983, to be published in VDI-Forsch. Ing.-Wes., $\underline{50},(1984)$.

[9] Dung, N.L., Newerla, A. and Marten, J., "FARM Finite Element Analysis of RigidPlastic Metal Forming - User's Manual", Institute of Mechanics, University of Hannover, Hannover, F.R. Germany, 1982. 